\title{
Fatigue Behaviour of Acrylic Matrix Composites: Influence of Seawater
}

\author{
Davies Peter ${ }^{1,{ }^{*}}$, Arhant Mael $^{1}$ \\ ${ }^{1}$ IFREMER Centre de Bretagne, Marine Structures Laboratory, 29280 Plouzané, France \\ * Corresponding author : Peter Davies, email address : peter.davies@ifremer.fr
}

\begin{abstract}
:
The recent introduction of liquid acrylic thermoplastic matrix resins which can impregnate fibre reinforcements using traditional infusion moulding offers significant potential for future composite structures in marine applications, such as marine energy devices. However, to date very few results are available to evaluate the long term durability of these composites in a marine environment. This paper describes results from a series of cyclic loading tests on glass and carbon fibre reinforced acrylic composites under both tension and four point flexural loading. Tests were performed before and after aging in natural seawater. The results were compared to results for a glass/epoxy used today in marine structures, and show a lower loss of both static and cyclic properties for glass/acrylic composites after seawater saturation. A carbon fibre reinforced acrylic composite was also tested. This showed excellent properties in tension, but poor out-of-plane properties due to manufacturing defects.
\end{abstract}

Keywords : Acrylic, Fatigue, Immersion, Seawater 


\section{Introduction}

Many marine structures use large quantities of composite materials in which glass or carbon fibres reinforce thermoset matrix resins such as polyesters and epoxies. The potential for recycling of such composites is limited, and there is increasing interest in alternative thermoplastic matrix polymers for boats, marine energy structures and offshore applications. There are many thermoplastics available, from the polyolefins to high performance polymers such as PEEK, but they require a step change in manufacturing technology; elevated temperatures and pressures are needed to impregnate fibre reinforcements with these high viscosity polymers. Many boatyards now use infusion to produce large components with epoxy resins so it would be very attractive to be able to keep infusion technology but to manufacture thermoplastic matrix composites. A recent development by Arkema aims to do this, using liquid, infusible, thermoplastic acrylic resins marketed under the Elium ${ }^{\mathrm{TM}}$ trademark [1]. These have attracted considerable interest since their introduction in 2013, and trials have been performed for racing yachts [2] and a wind turbine blade [3]. However, due to the recent introduction of the Elium ${ }^{\mathrm{TM}}$ 
acrylic resin there are few mechanical property data available. Results from tensile tests on matrix resin indicated a modulus around $3 \mathrm{GPa}$, similar to common epoxy resins.

Boufaida et al [4] showed in-plane shear properties for woven glass reinforced acrylic composites, while Davies et al [5] showed tensile properties for glass and carbon reinforced acrylic. Overall properties were similar to those expected for reinforced thermoset matrix composites. The importance of an appropriate glass fibre sizing was revealed by tests comparing a multi-compatible sizing and a specific acrylic sizing. The latter allowed larger in-plane shear stresses to be reached before failure [4]. Some cyclic tests with heat build-up measurements were also performed during this study and results suggested that the damage threshold may increase when fibres are coated with a specific acrylic fibre sizing. Beguinel et al also discussed specific fibre sizings for acrylic matrix composites and used microdroplet debonding to characterize the improvement in interfacial shear strength [6].

There have also been some studies of fracture toughness of neat resin and composites. An interlaminar crack propagation value of around $1000 \mathrm{~J} / \mathrm{m}^{2}$ was measured on infused carbon/acrylic, significantly higher than the unreinforced matrix toughness values ( 0.3 to $0.6 \mathrm{~kJ} / \mathrm{m}^{2}$ according to loading rate) [7]. Another study reported improved interlaminar crack propagation resistance of carbon/acrylic compared to a carbon/epoxy, and showed good acrylic adhesion to carbon fibres [8]. Some data are also available for low velocity impact response of glass reinforced acrylic and toughened formulations to which different amounts of acrylic tri-block copolymers were added [9]. Under some conditions the latter resulted in improved impact performance.

With respect to the marine environment some results are available for the influence of seawater aging on static properties of acrylic matrix and glass and carbon fibre reinforced composites [5]. It was shown that the acrylic matrix resin is very stable in seawater, showing lower property losses after seawater aging than those of a commonly-used marine epoxy matrix resin. Carbon fibre reinforced acrylic also shows good property retention after aging, while reductions in glass fibre reinforced composite strengths suggested that specific glass fibre sizing might be required for optimum durability. Chilali et al [10] examined the effect of tap water immersion at $20^{\circ} \mathrm{C}$ on woven flax/epoxy and flax/acrylic composites; they noted similar large drops in properties for both materials after aging, but it is the fibres rather than the matrix which dominates the behviour in such materials.

Finally, with respect to fatigue properties very few data are available at the time of writing. There are some recent results for acrylic composites with natural fibre reinforcements [11]. Haggui et al followed tension fatigue tests on unidirectional and $0 / 90^{\circ}$ flax reinforced acrylic with acoustic emission but there was no comparison with other materials.

This brief overview underlines a clear lack of data on which to base an evaluation of the long term durability of acrylic matrix composites. This was the reason for the present study, which aims to 
provide a quantitative comparison of the fatigue behavior of these materials with that of a glass/epoxy marine composite. The effect of seawater immersion on this behavior has also been examined.

\section{Materials and Methods}

Table 1 shows the details of the three materials tested.

\begin{tabular}{|c|c|c|c|c|c|c|}
\hline $\begin{array}{l}\text { Material, fibre areal } \\
\text { weight (nominal), } \\
\text { lay-up }\end{array}$ & Resin & $\begin{array}{c}\text { Thickness, } \\
\text { mm } \\
\text { (20 points } \\
\text { on panel) }\end{array}$ & $\begin{array}{c}\mathrm{Tg},{ }^{\circ} \mathrm{C} \\
\mathrm{DSC}\end{array}$ & $\begin{array}{c}\text { Density, } \\
\mathrm{g} / \mathrm{cm}^{3}, \\
\text { helium } \\
\text { pycnometer }\end{array}$ & $\begin{array}{c}\mathrm{V}_{\mathrm{f}} \\
\text { Estimated } \\
\text { from } \\
\text { density }\end{array}$ & $\begin{array}{l}\text { ILSS, } \\
\mathrm{MPa}\end{array}$ \\
\hline $\begin{array}{c}\text { Carbon/Acrylic } \\
0: \text { UD } \\
\text { X: } \pm 45^{\circ} \\
\text { Sequence: } 0 \text { XXX } 0\end{array}$ & Elium 180 & $3.71(0.12)$ & 75 & 1.538 & 0.57 & $\begin{array}{l}40.2^{*} \\
(1.4)\end{array}$ \\
\hline $\begin{array}{c}\text { E-glass/Acrylic } \\
0 \text { : UD } \\
\text { X: } \pm 45^{\circ} \\
\text { Special acrylic sizing } \\
\text { Sequence: } 0 \text { XX } 0\end{array}$ & Elium 180 & $3.12(0.08)$ & 89 & 1.923 & 0.52 & $\begin{array}{l}46.0 \\
(1.4)\end{array}$ \\
\hline $\begin{array}{c}\text { E-glass/Epoxy } \\
0: \text { UD } \\
\text { X: } \pm 45^{\circ} \\
\text { Sequence: } 0 \text { XX } 0\end{array}$ & $\begin{array}{c}\text { CeTePox }{ }^{\circledR} \\
\text { AM3321 }\end{array}$ & $3.05(0.07)$ & 85 & 1.914 & 0.53 & $\begin{array}{l}38.1 \\
(2.7)\end{array}$ \\
\hline
\end{tabular}

*Compression failure, not delamination

Table 1. Materials tested.

These three materials were manufactured by infusion at a high performance boatyard, in the form of $(400 \mathrm{x} 400) \mathrm{mm}^{2}$ panels. They were all post-cured for 12 hours at $65^{\circ} \mathrm{C}$.

The stacking sequence $\left(0^{\circ}\right.$ outer and $\pm 45^{\circ}$ inner layers) was chosen as it represents the material for a particular tidal energy recovery device under development. Figure 1 shows optical microscope images of sections through the glass/acrylic and carbon/acrylic composites, the glass/epoxy is very similar to the glass/acrylic. In the central $\pm 45^{\circ}$ layers of the carbon/acrylic there appear to be defects, these will be discussed in more detail in the Results section below. 

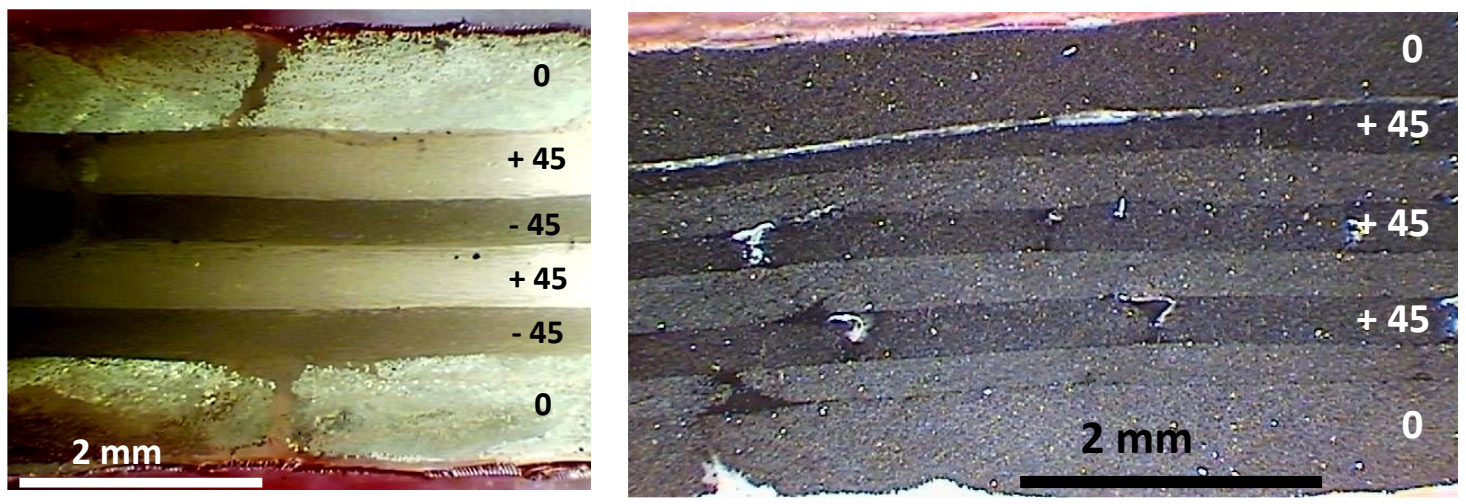

Figure 1. Micrographs of cross-sections through glass/acrylic and carbon/acrylic composites.

Figure 1 shows that while the $0^{\circ}$ layers are symmetrical with respect to the mid-plane the lay-up of the $45^{\circ}$ plies does not show mirror symmetry. Interlaminar shear tests were performed for quality control of the panels, following ASTM 2344, at a loading rate of 5mm/minute. Apparent shear strength values are given in Table 1. However, it should be noted that the carbon/acrylic specimens failed in compression, not due to delamination, so those values are not valid. Some ILSS tests were also performed after aging for 18 months, both in the wet condition and after drying at $40^{\circ} \mathrm{C}$ in a desiccator to constant weight. The main series of mechanical tests was performed on two hydraulic test frames, a $25 \mathrm{kN}$ Zwick test frame for four point flexure $(120 \times 25) \mathrm{mm}^{2}$ specimens with $50 \mathrm{~mm}$ between upper loading points and $100 \mathrm{~mm}$ between lower supports, and a $250 \mathrm{kN}$ MTS machine with hydraulic grips for tensile tests $(250 \times 25) \mathrm{mm}^{2} 150 \mathrm{~mm}$ free length. R-ratio was 0.1 , frequency was $1 \mathrm{~Hz}$ in tension and $2 \mathrm{~Hz}$ in flexure. All flexural tests were performed immersed in continuously renewed seawater at $25^{\circ} \mathrm{C}$. Tension tests were performed in air but saturated specimens were kept in seawater at $20^{\circ} \mathrm{C}$ until testing and specimens were wrapped in plastic film during cycling to limit evaporation. All tensile tests were performed with bonded, tapered $\pm 45^{\circ}$ glass/epoxy end tabs at both specimen ends. Aging was performed by immersion of specimens in continuously renewed natural seawater aging tanks. One additional $(50 \times 50) \mathrm{mm}^{2}$ coupon of each material was immersed at 4, 25, 40 and $60^{\circ} \mathrm{C}$ and then removed and weighed regularly on a Sartorius balance to examine diffusion kinetics. Tensile and flexural specimens were immersed at $60^{\circ} \mathrm{C}$ and removed for testing when they were saturated with water (weight stabilization). Fracture surfaces were examined in a Philips FEI Quanta 200 scanning electron microscope.

\section{Results}

Immersion

Figure 2 shows examples of weight gains for the glass reinforced materials at different temperatures. For the glass/epoxy the weight at saturation was around $1.2 \%$ by weight, it took around eight months 
to reach this plateau at $60^{\circ} \mathrm{C}$. For the glass/acrylic the weight stabilized more quickly at a much lower level, around $0.4 \%$, and the tests on saturated specimens were performed after four months in seawater at $60^{\circ} \mathrm{C}$. The carbon reinforced acrylic saturated at around $0.5 \%$ by weight after a similar period.
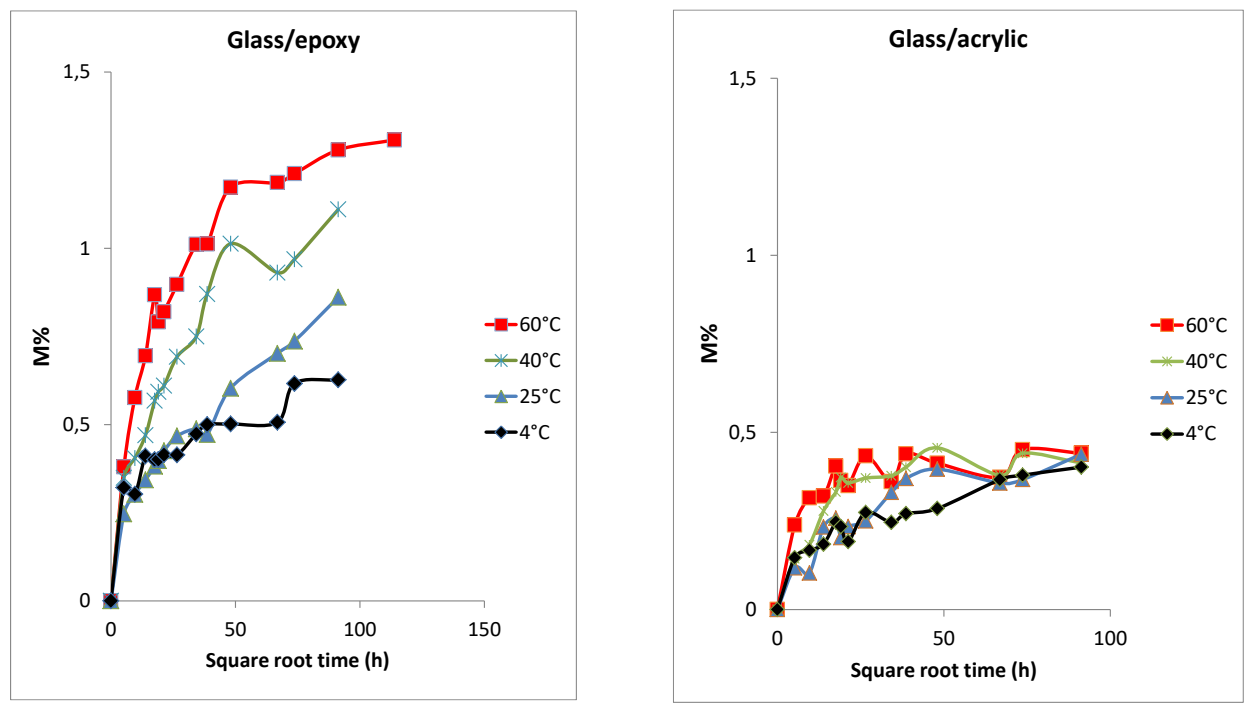

Figure 2. Weight gains of glass reinforced composites after seawater immersion for one year at different temperatures.

Coupons nominally $3 \mathrm{~mm}$ thick. Additional data-point at 18 months for glass/epoxy at $60^{\circ} \mathrm{C}$, to check plateau reached.

\section{- $\quad$ Static tests}

Table 2 shows results from tensile and flexural tests on the three materials. The glass reinforced composites were tested in the dry and saturated states, the carbon composites were only tested asreceived in flexure.

\begin{tabular}{|l|c|c|c|c|}
\hline Material, Condition & \multicolumn{2}{|c|}{ Tensile properties } & \multicolumn{2}{c|}{ Flexural properties } \\
\hline Glass/epoxy & $\begin{array}{c}\text { Tensile modulus, } \\
\text { GPa }\end{array}$ & $\begin{array}{c}\text { Tensile failure } \\
\text { stress, MPa }\end{array}$ & $\begin{array}{c}\text { Flexural } \\
\text { modulus, GPa }\end{array}$ & $\begin{array}{c}\text { Flexural failure } \\
\text { stress, MPa }\end{array}$ \\
As-received & $24.9(0.2)$ & $443(30)$ & $38.2(3.2)$ & $606(55)$ \\
Aged & $22.2(0.6)$ & $262(3)$ & $36.3(1.3)$ & $255(50)$ \\
\hline Glass/Acrylic & & & & \\
As-received & $27.5(0.5)$ & $568(18)$ & $40.1(2.1)$ & $703(11)$ \\
Aged & $25.4(0.6)$ & $377(17)$ & $43.5(0.2)$ & $512(21)$ \\
\hline Carbon/Acrylic & & & & \\
As-received & $71.9(0.2)$ & $831(42)$ & $102.7(6.4)$ & $589.5(44)$ \\
Aged & $67.4(6.2)$ & $801(27)$ & - & - \\
\hline
\end{tabular}


Table 2. Influence of aging on quasi-static tensile properties. Mean values with standard deviations in brackets.

Saturation in seawater results in a small drop (5-10\%) in tensile stiffness in the $0^{\circ}$ direction. The tensile strength changes are more important for the glass reinforced composites; $41 \%$ and $34 \%$ reductions for the epoxy and acrylic, while the carbon/acrylic strength changes by less than $5 \%$. The behavior of this lay-up in flexure, with $0^{\circ}$ plies on the outer surfaces and off-axis plies in the centre, is similar to that of a sandwich material. The strong influence of the outer plies in flexure results in larger apparent flexural modulus than tensile modulus.

Flexural modulus changes after saturation are again small for the glass reinforced composites. However, there are significant changes in flexural strength. The glass/epoxy composite loses $58 \%$ of its initial strength after saturation, while the change for the acrylic composite is much smaller, around $27 \%$. Failure occurs in compression on the upper surface of the glass/epoxy flexural specimens and by delamination for the glass/acrylic.

The flexural strength of the carbon/acrylic before aging is significantly lower than its tensile strength, and even lower than that of the as-received glass reinforced composites. This is unexpected, and specimens were examined using both optical and scanning electron microscopy. Failure occurred by delamination at the $45^{\circ}$ layer interfaces, and investigation of specimens indicated voids originating close to the PET binder yarn holding the +45 and $-45^{\circ}$ layers together, Figure 3 .
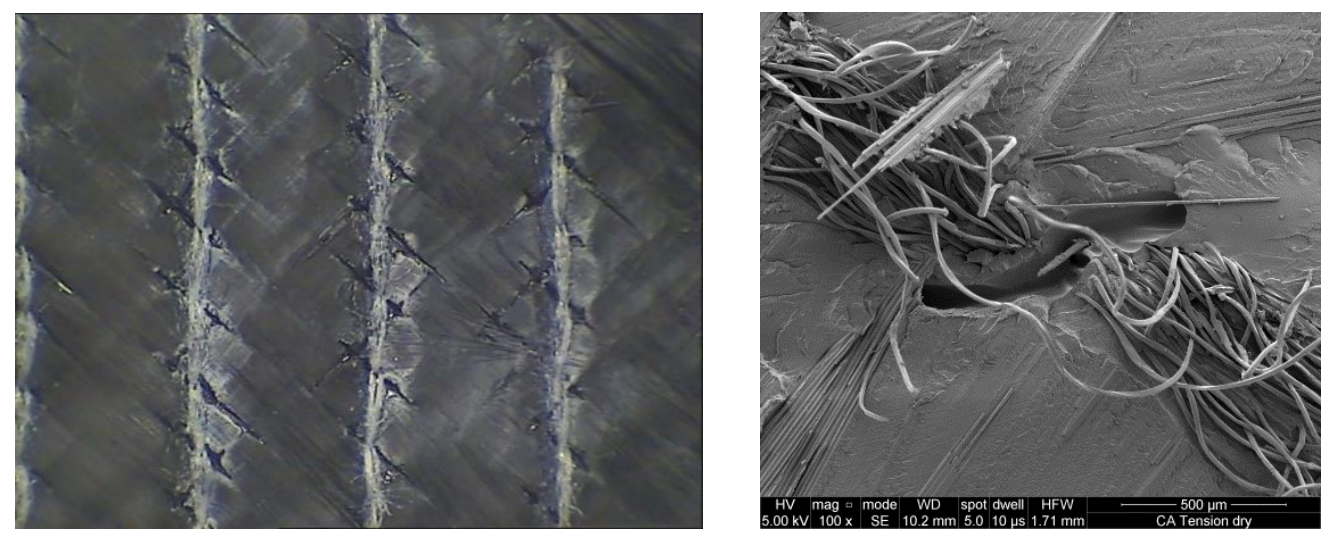

Figure 3. Binder yarn on carbon/acrylic flexural fracture surface and SEM image of void at binder yarn.

These defects probably also explain the invalid ILSS results in Table 1. For this reason seawater aging was not performed on flexural specimens of this material.

- Cyclic tests 
a) Tension fatigue

Figure 4 shows the results from tensile fatigue tests on the three composites before immersion.

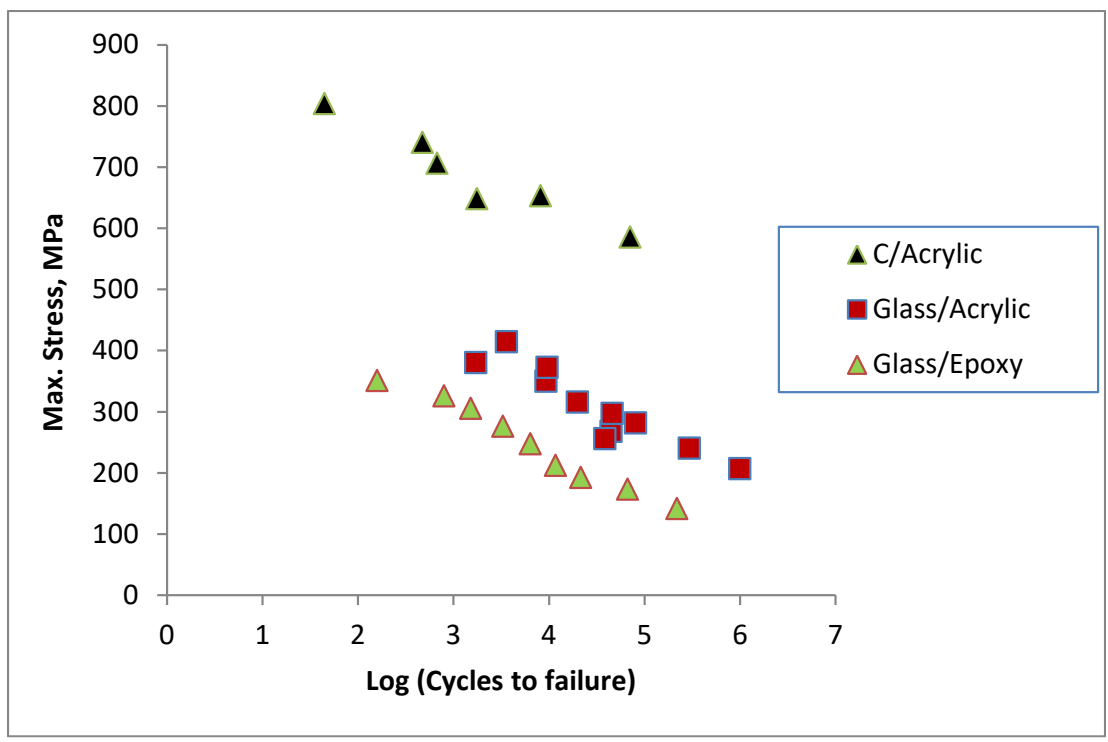

Figure 4. Tensile fatigue, as-received specimens

Figure 5 shows the results for the three materials after saturation.

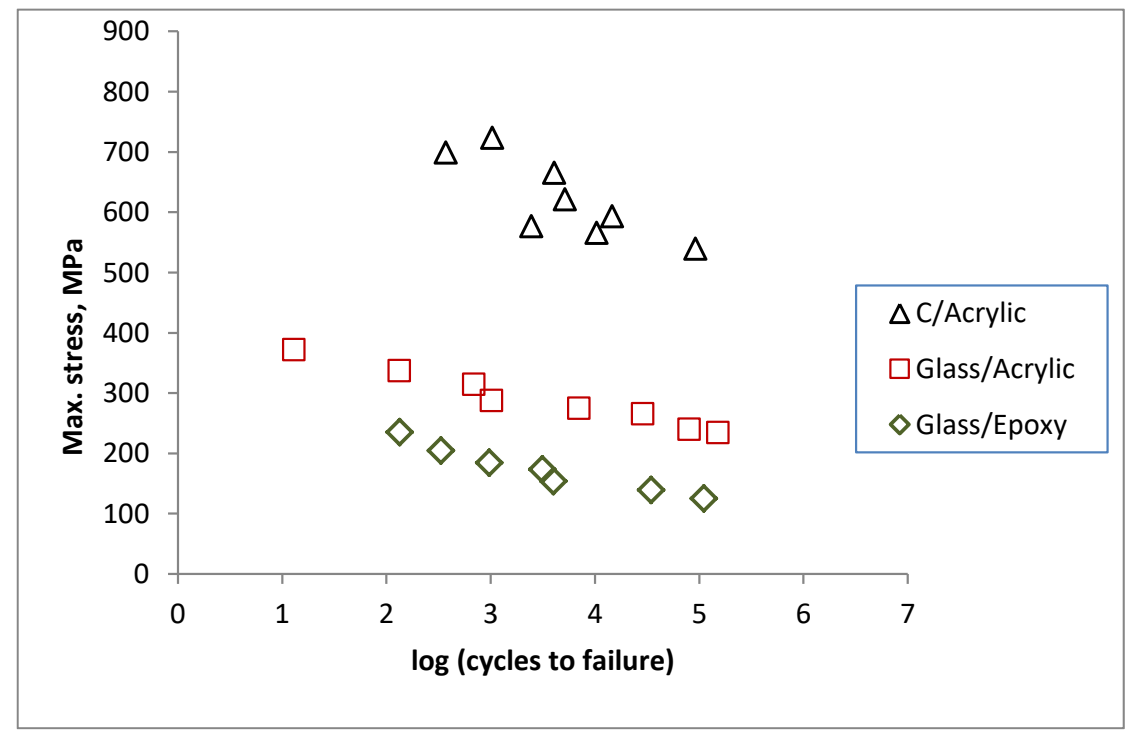

Figure 5.Tensile fatigue results, seawater saturated specimens

Figure 6 shows all results normalized by the unaged tensile static failure stress, in order to evaluate the fatigue performance with respect to the initial nominal design stress. 


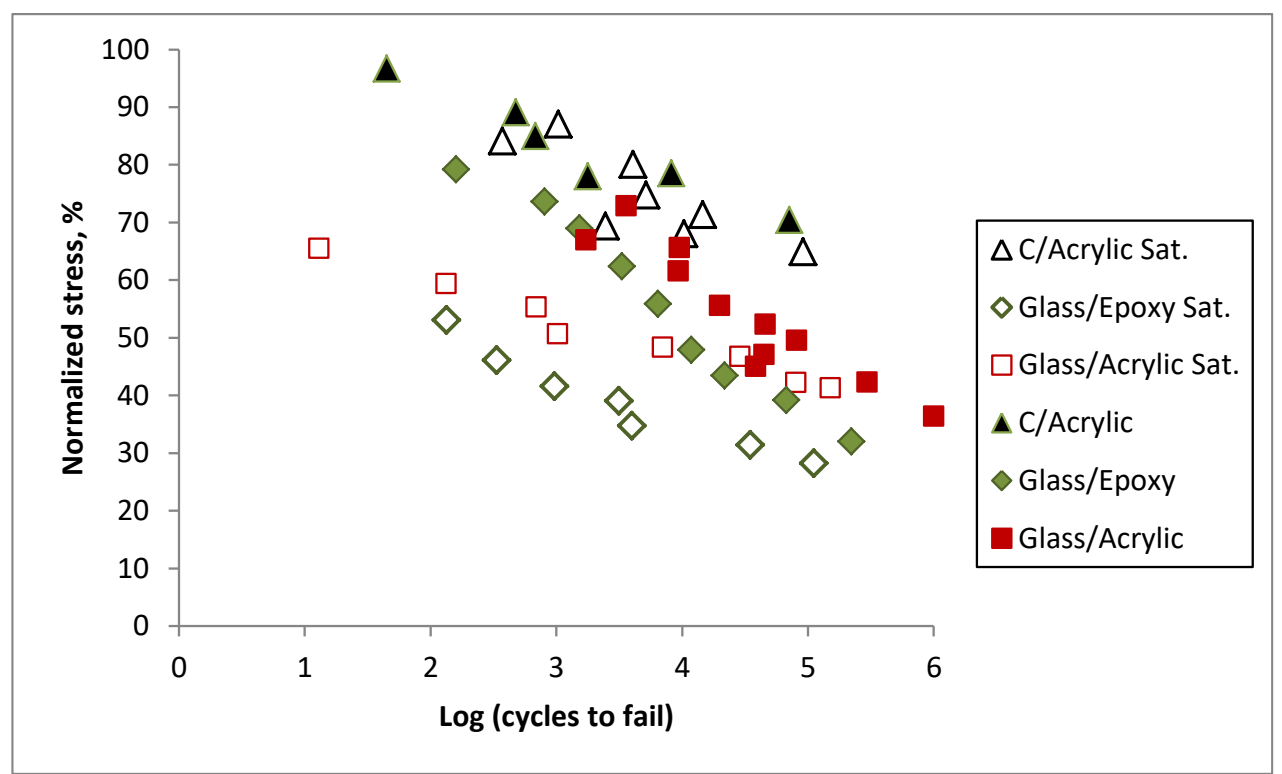

Figure 6. Normalized stress (maximum applied stress/dry tensile strength) as a function of fatigue lifetimes.

As-received and saturated samples tested in tension.

These plots show that the tensile fatigue performance of the carbon/acrylic is hardly affected by seawater saturation, whereas the glass reinforced composite lifetimes are significantly reduced at high loads. In order to reach $10^{5}$ cycles the saturated glass/acrylic composite can support cycling up to around $40 \%$ of its dry static strength while for the wet glass/epoxy the maximum allowable stress value is below $30 \%$. For comparison, the saturated carbon/acrylic could be cycled up to around $70 \%$ of its dry tensile strength for $10^{5}$ cycles before failure.

b) Flexural fatigue

Figure 7 shows results from flexural fatigue cycling of unaged specimens.

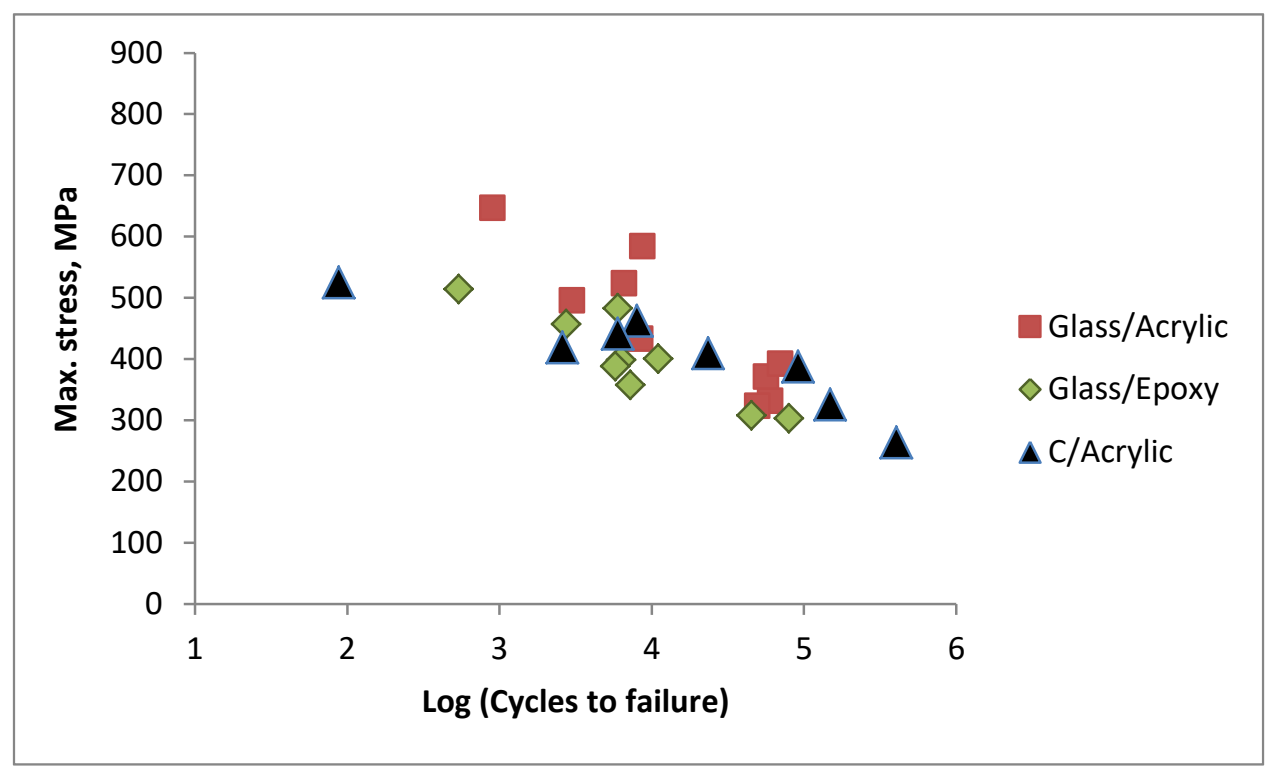


Figure 7. Flexural fatigue, unaged specimens.

Here there is little difference between the three unaged materials; this is not unexpected given the very low static flexural results for the carbon/acrylic shown in Table 2, but it clearly shows the importance of studying different loading configurations when evaluating new materials; results in tension for this material were as expected. The carbon/acrylic composite again failed by delamination in all flexural fatigue tests, within the $45^{\circ}$ layers, not at the $0^{\circ} / 45^{\circ}$ interfaces. The glass/acrylic lifetimes are slightly higher than those of the glass/epoxy composites but within experimental scatter.

Figure 8 shows a comparison between the normalized flexural fatigue strengths of the two glass reinforced composites before and after saturation in seawater. As for the tension cycling there is a strong effect of seawater on the fatigue behaviour of both materials in flexure.

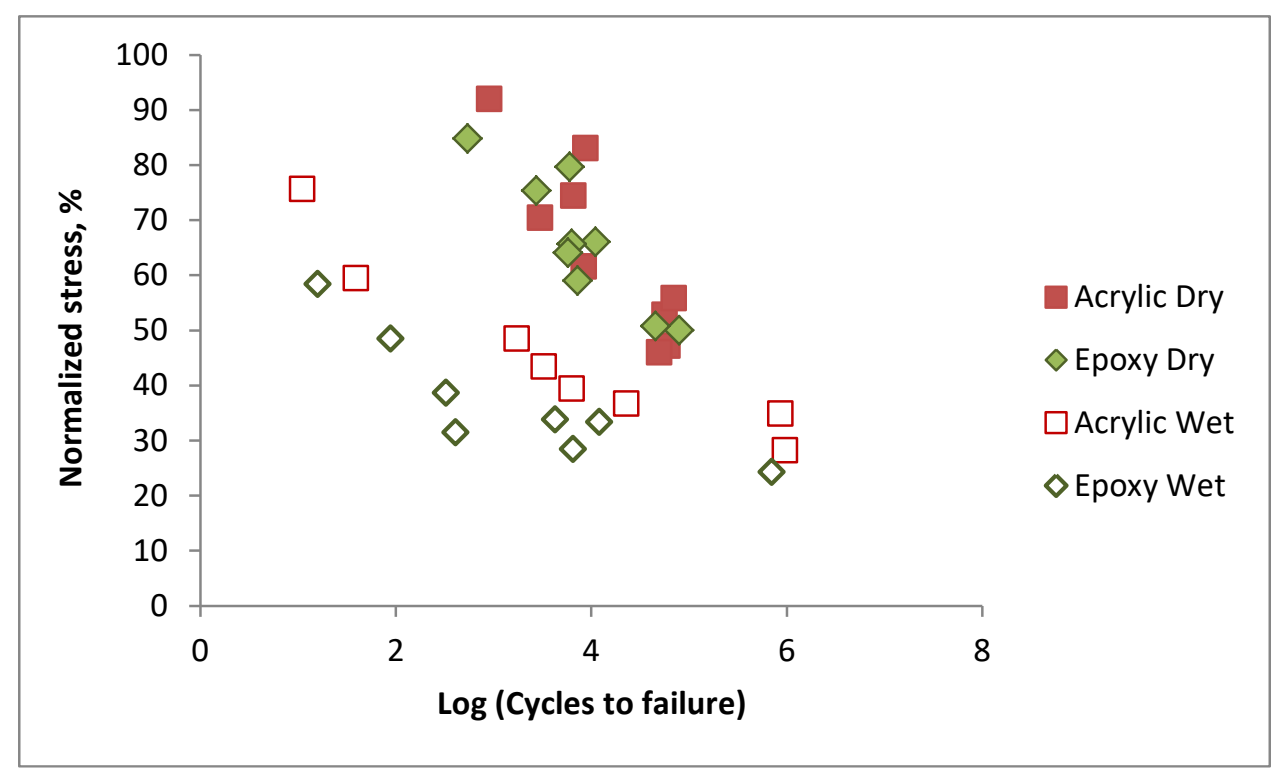

Figure 8. Normalized stress (maximum applied stress/dry flexural strength) as a function of fatigue lifetimes.

As-received and saturated samples tested in flexure.

Figure 9 summarizes the mechanical properties of the two glass reinforced composites before and after seawater saturation. In order to compare fatigue performance interpolated stress values at an arbitrary lifetime of $10^{5}$ cycles are shown, based on linear regression analysis of stress versus log (cycles to failure) plots. This figure shows that the higher tensile and flexural quasi-static properties of the acrylic composites are transferred to the fatigue properties but that there is significantly higher property retention of the glass/acrylic after saturation in seawater. 


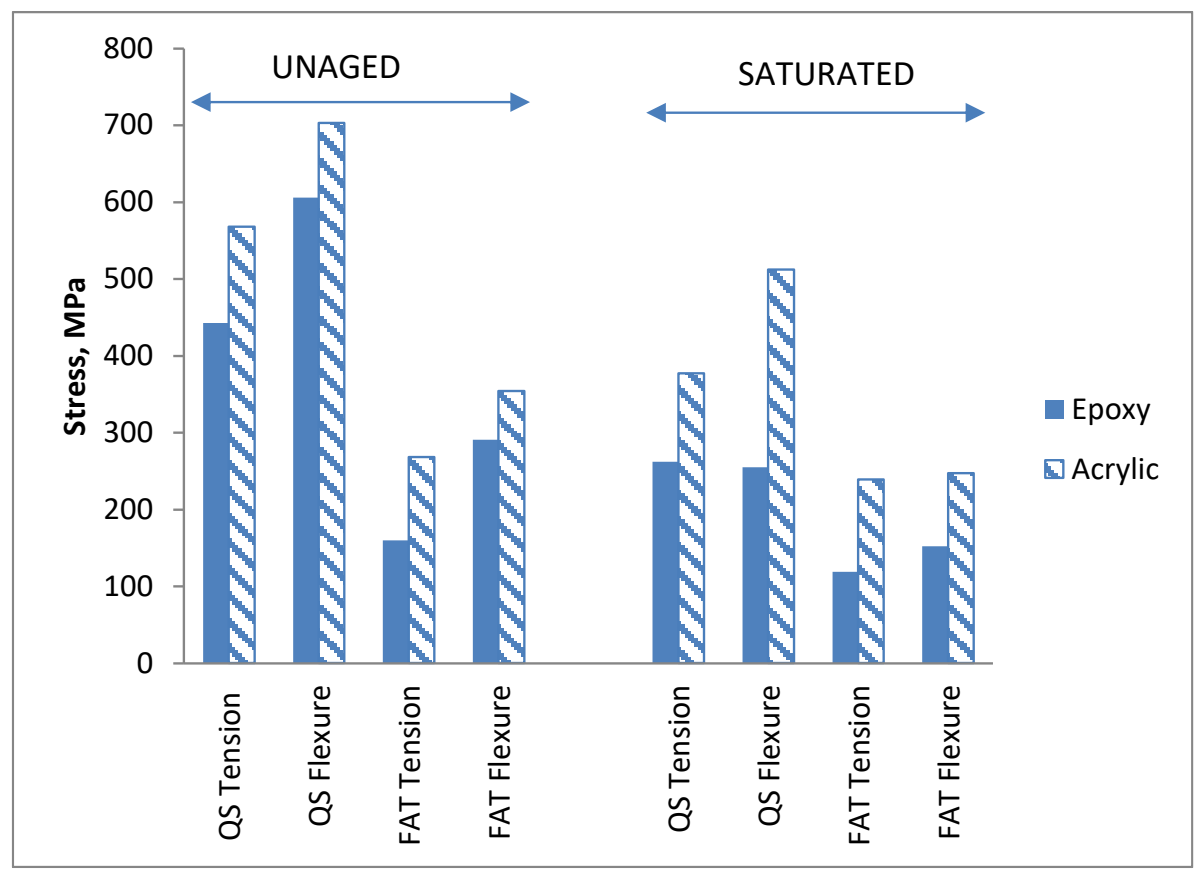

Figure 9. Comparison between quasi-static (QS) and maximum allowable fatigue (FAT) failure stresses at $10^{5}$ cycles.

Glass/epoxy and glass/acrylic, before and after saturation in seawater.

\section{Discussion}

Published results on the influence of seawater on unreinforced acrylic resin static tensile properties show that the main effect is plasticization [5]. There is a $20 \%$ reduction in polymer tensile strength with increasing water content but on drying the initial strength is recovered. In the present study the glass fibres were coated with a specific sizing developed for acrylic matrix. The loss in composite strength here for the saturated glass reinforced acrylic is around 35\%. In that previous work a standard glass fibre reinforcement was tested in a $0 / 90^{\circ}$ configuration, with a multi-compatible sizing [5]. It was noted that after saturation in seawater the drop in strength was around 50\%, little of which was recovered after drying. This suggests that the specific sizing used here improves property retention. Figure 10 shows fracture surfaces of unaged and saturated specimens. The fibre coating is very extensive in the dry samples but the wet samples show some clean fibres. This indicates that there may be some additional interface improvement possible. 


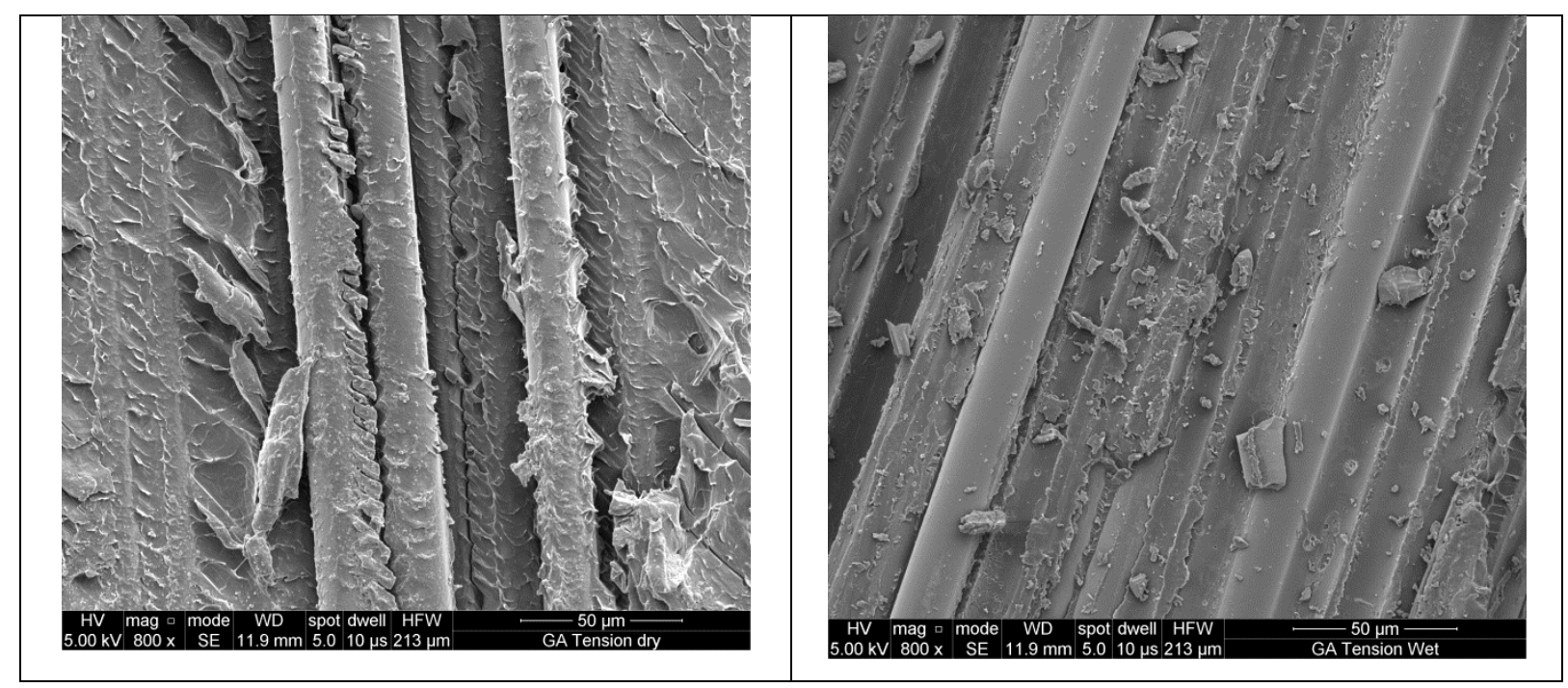

Figure 10. Tension fatigue fracture surfaces, glass/acrylic. Left: Dry. Right:Wet

The glass/epoxy sample fracture surfaces show clean fibres even when tested dry, Figure 11. Resin cusps similar to those described by Purslow [12] are visible on fracture surfaces.

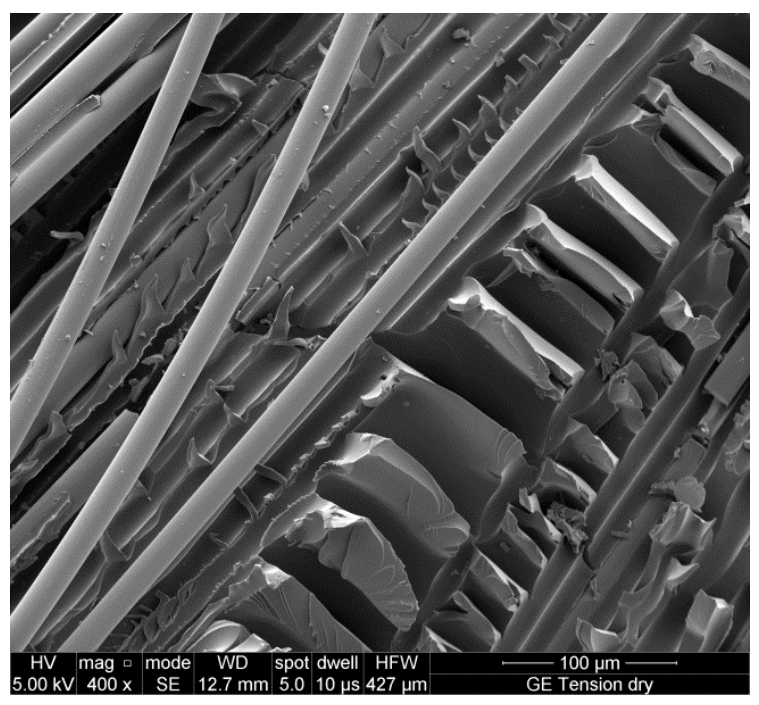

Figure 11. Glass/epoxy tensile fatigue fracture, $45^{\circ}$ layer, dry.

There were two distinct failure modes for the glass reinforced composites under cyclic flexural loading. All the epoxy composites failed by upper face compression, before and after aging, while all the glass/acrylic composites failed by delamination, sometimes within the $0^{\circ}$ layers and sometimes at the $0 / 45^{\circ}$ interfaces, Figure 12 . 

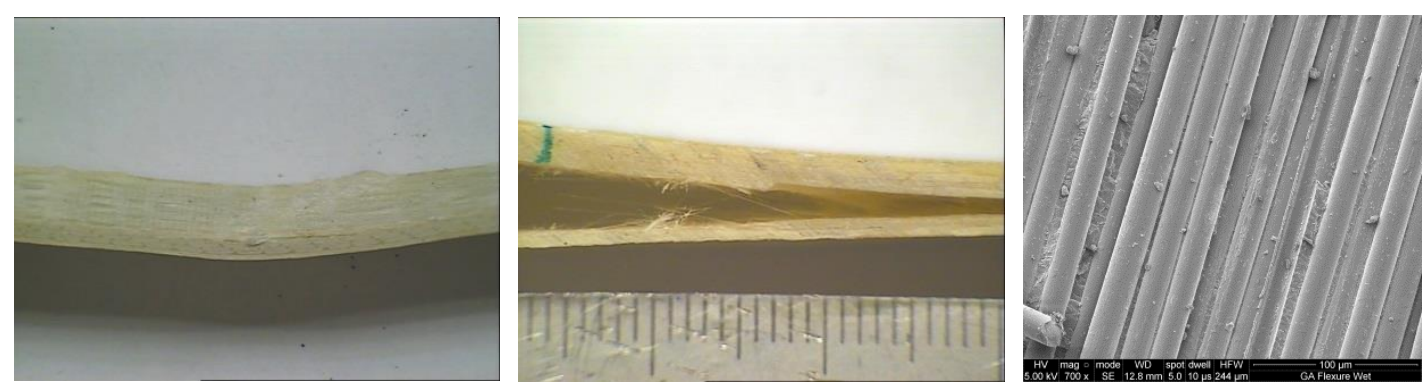

Figure 12. Flexural fatigue fracture.

Left: glass/epoxy, upper surface compression buckling; centre: glass/acrylic delamination, green line indicates upper load point); right: glass/acrylic fracture surface.

Despite similar resin properties, flexural stiffnesses and stacking sequences there is a distinct difference in failure modes between the two glass fibre reinforced materials when tested in flexure; compression and delamination. Both failure modes are sensitive to resin and fibre/matrix interface properties. Interlaminar shear tests are also sensitive to the integrity of this region and a set of samples was aged for 18 months, then tested both wet and after drying to constant weight. Figure 13 shows the results, mean values from 4 tests at each condition.

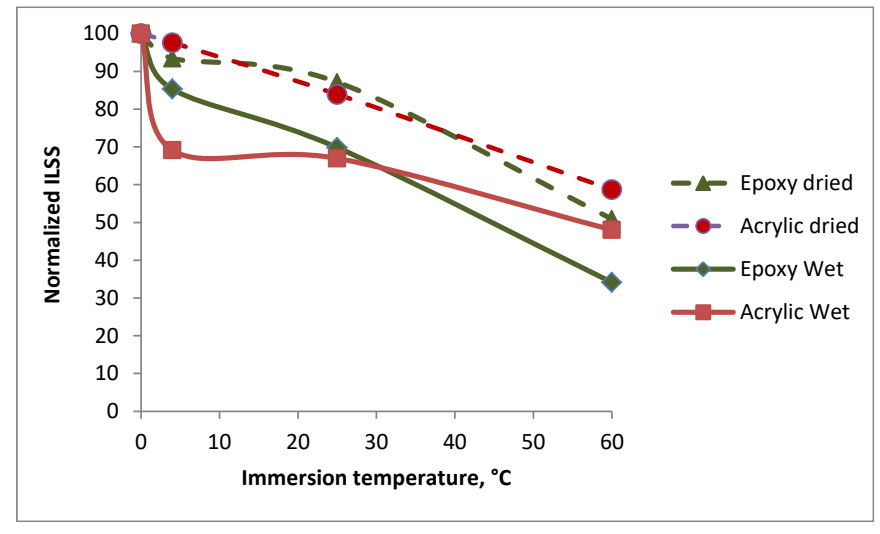

Figure 13. ILSS test results, glass reinforced composites.

Tested wet after 18 months' immersion at different temperatures, and after drying, all values normalized by initial unaged values.

Both materials show mainly reversible ILSS reductions at the lower temperatures while the $60^{\circ} \mathrm{C}$ immersion results in a large permanent drop in apparent shear strength. The drop in properties is more rapid for the acrylic composite than for the glass/epoxy at $4^{\circ} \mathrm{C}$ but slower at $60^{\circ} \mathrm{C}$. However, as the seawater diffusion kinetics are much slower for the latter it is not saturated with water at 4 or $25^{\circ} \mathrm{C}$ even after 18 months, whereas the glass/acrylic is saturated at all three temperatures. The initial loss of strength is related to matrix plasticization but the large drop after 18 months at $60^{\circ} \mathrm{C}$, together with the 
images in Figure 10, suggests that interfacial degradation is the main reason for the large loss in properties after prolonged immersion.

It would be interesting to examine the compression behaviour and interlaminar fracture toughness of these composites by specific tests, in order to obtain additional information on how water affects the failure mechanisms in the two materials.

Finally, the S-N plots obtained for these two materials can be compared to published data from flexural tests performed on the same machines under similar conditions even though most previous tests have been performed on unidirectional composites. The normalized losses in flexural strengths measured here on unaged specimens (17\%/decade for the glass/epoxy, $21 \% /$ decade for the glass/acrylic) are higher than the 9 to $13 \% /$ decade range of values reported for other glass epoxy and basalt/epoxy unidirectional composites $[13,14]$, but this is not unexpected due to the presence of $\pm 45^{\circ}$ layers here.

\section{Conclusions}

Liquid infusible acrylic thermoplastic resins are being proposed for a range of marine applications, but due to their recent introduction little is known of their long term behavior in a marine environment. This paper presents results from static and fatigue tests under tensile and flexural loading. The results show that the fatigue behavior of the glass/acrylic, both dry and after saturation with seawater, is at least as good as that of a glass reinforced marine epoxy with similar fibre content.

A carbon/acrylic composite was also evaluated, and showed excellent property retention under tensile fatigue loading. However, manufacturing defects in this material, linked to the binder yarn, resulted in poor out-of-plane properties.

\section{Acknowledgements}

The authors gratefully acknowledge the important contribution of Nicolas Gayet of Ifremer to the SEM study.

\section{References}

[1] https://www.arkema.com/en/products/product-finder/product-viewer/Elium-for-infusion/ 
[2] Roucayrol L, Neyhousser R, Gerard P, Cledat G, Arkema 3 Mini 6.50: a model of innovation, JEC Composites Magazine, 115, August 2017, 41-43

[3] https://www.arkema.com/en/media/news/news-details/Composites-innovation-manufacturing-of-awind-turbine-blade-in-Eliumsup-sup-thermoplastic/

[4] Boufaida Z, Farge L, André S, Meshaka Y, Influence of the fiber/matrix strength on the mechanical properties of a glass fiber/thermoplastic-matrix plain weave fabric composite, Composites: Part A 75 (2015) 28-38

[5] Davies P, Le Gac P-Y, Le Gall M, Influence of Sea Water Aging on the Mechanical Behaviour of Acrylic Matrix Composites, Appl Compos Mater (2017) 24:97-111

[6] Beguinel J, Gérard J-F, Lortie F, Gérard P, Maupetit J, New Continuous Fiber Reinforced Thermoplastic Composites: An analysis of Interfacial Adhesion from the micro scale to the macro scale, Proc. 20th International Conference on Composite Materials, Copenhagen, 19-24th July 2015

[7] Pini T, Briatico-Vangosa F, Frassine R, Rink M, Time dependent fracture behaviour of a carbon fibre composite based on a (rubber toughened) acrylic polymer, Structural Integrity Procedia 2, (2016) 253-260

[8] Bhudolia SK, Perrotey P, Joshi SC, Mode I fracture toughness and fractographic investigation of carbon fibre composites with liquid Methylmethacrylate thermoplastic matrix, Composites Part B 134 (2018) 246-253

[9] Matadi Boumbimba R, Coulibaly M, Khabouchi A, Kinvi-Dossou aG, Bonfoh N, Gerard P, Glass fibres reinforced acrylic thermoplastic resin-based tri-block copolymers composites: Low velocity impact response at various temperatures, Composite Structures 160 (2017) 939-951

[10] Chilali A, Zouari W, Assarar M, Kebir H, Ayad R, Effect of water ageing on the load-unload cyclic behaviour of flax fibre-reinforced thermoplastic and thermosetting composites, Composite Structures 183 (2018) 309-319

[11] Haggui M, El Mahi A, Jendli Z, Akrout A, Haddar M, Static and fatigue characterization of flax fiber reinforced thermoplastic composites by acoustic emission, Applied Acoustics, Published on-line, March 2018.

[12] Purslow D, Matrix fractography of fibre reinforced epoxy composites, Composites, 17, 94, (1986), 289-303.

[13] Boisseau A, Davies P, Thiebaud F, Fatigue Behaviour of Glass Fibre Reinforced Composites for Ocean Energy Conversion Systems, Applied Composite Materials, Vol 20, issue 2 pp145-155, 2013 
[14] Davies P, Verbouwe W. Evaluation of Basalt Fibre Composites for Marine Applications. Applied Composite Materials, (2018) 25:299-308 


\section{Figure Titles and Legends}

Figure 1. Micrographs of cross-sections through glass/acrylic and carbon/acrylic composites.

Figure 2. Weight gains of glass reinforced composites after seawater immersion for one year at different temperatures.

Coupons nominally $3 \mathrm{~mm}$ thick. Additional data-point at 18 months for glass/epoxy at $60^{\circ} \mathrm{C}$, to check plateau reached.

Figure 3. Binder yarn on carbon/acrylic flexural fracture surface and SEM image of void at binder yarn.

Figure 4. Tensile fatigue, as-received specimens

Figure 5.Tensile fatigue results, seawater saturated specimens

Figure 6. Normalized stress (maximum applied stress/dry tensile strength) as a function of fatigue lifetimes.

As-received and saturated samples tested in tension.

Figure 7. Flexural fatigue, unaged specimens.

Figure 8. Normalized stress (maximum applied stress/dry flexural strength) as a function of fatigue lifetimes.

As-received and saturated samples tested in flexure.

Figure 9. Comparison between quasi-static (QS) and maximum allowable fatigue (FAT) failure stresses at $10^{5}$ cycles.

Glass/epoxy and glass/acrylic, before and after saturation in seawater.

Figure 10. Tension fatigue fracture surfaces, glass/acrylic. Left: Dry. Right:Wet 
Figure 11 . Glass/epoxy tensile fatigue fracture, $45^{\circ}$ layer, dry.

Figure 12. Flexural fatigue fracture.

Left: glass/epoxy, upper surface compression buckling; centre: glass/acrylic delamination, green line indicates upper load point); right: glass/acrylic fracture surface.

Figure 13. ILSS test results, glass reinforced composites.

Tested wet after 18 months' immersion at different temperatures, and after drying, all values normalized by initial unaged values. 